\title{
Antibiotic Resistance of Helicobacter pylori and Eradication Rate in Japanese Pediatric Patients
}

\author{
Tamaki Ikuse'1,2, Yo Aoyagi', Naho Obayashi' ${ }^{1}$, Keisuke Jimbo'1, Takahiro Kudo', \\ Yoshikazu Ohtsuka1, Thomas G. Blanchard ${ }^{2}$, Steven J. Czinn' ${ }^{2}$, Toshiaki Shimizu1 \\ ${ }^{1}$ Department of Pediatric and Adolescent Medicine, Juntendo University Graduate School of Medicine, Tokyo, Japan \\ ${ }^{2}$ Department of Pediatrics, University of Maryland School of Medicine, Baltimore, USA \\ Email: taikuse@juntendo.ac.jp
}

How to cite this paper: Ikuse, T., Aoyagi, Y., Obayashi, N., Jimbo, K., Kudo, T., Ohtsuka, Y., Blanchard, T.G., Czinn, S.J. and Shimizu, T. (2017) Antibiotic Resistance of Helicobacter pylori and Eradication Rate in Japanese Pediatric Patients. Advances in Microbiology, 7, 241-252.

https://doi.org/10.4236/aim.2017.74020

Received: March 1, 2017

Accepted: April 16, 2017

Published: April 19, 2017

Copyright (c) 2017 by authors and Scientific Research Publishing Inc. This work is licensed under the Creative Commons Attribution International License (CC BY 4.0).

http://creativecommons.org/licenses/by/4.0/ (c) (†) Open Access

\begin{abstract}
Helicobacter pylori (H. pylori) eradication rates achieved with a proton pump inhibitor (PPI), amoxicillin and clarithromycin have recently decreased to about $75 \%$ because of the increase in clarithromycin resistance in Japan. In the present study, H. pylori resistance rates against clarithromycin, amoxicillin and metronidazole were investigated in pediatric patients and eradication rates were evaluated when tailored antibiotics regimens based on antibiotic sensitivity data were used. We isolated $H$. pylori endoscopically from 77 pediatric patients suffering from abdominal symptoms. The susceptibility tests of $H$. pylori strains to clarithromycin, amoxicillin and metronidazole were examined and eradication therapy was tailored using the appropriate antibiotics. Seventy-seven patients were treated with a mean age of $12.16 \pm 3.34$ years (range, 4.92 - 19.75) consisting of 40 males and 37 females. The average resistance rates between 1998 and 2016 to clarithromycin, amoxicillin and metronidazole were 54.5\% (42 of 77), 6.5\% (5 of 77) and 5.2\% (4 of 77) respectively. The prevalence of clarithromycin resistance increased significantly over time to reach $88.9 \%$ by $2013-2016$. Successful eradication rates using tailored antibiotic treatment was $93.8 \%$ (61 of 65). Clarithromycin-based eradication therapy rate reached $92.6 \%$ against clarithromycin-sensitive strains. Metronidazole-based initial eradication therapy also had a high successful rate (97.0\%) to clarithromycin-resistant strains. Although high rates of clarithromycin resistant $H$. pylori reaching about $90 \%$ were observed in Japanese children, tailored eradication therapy using the appropriate antibiotic agents were highly successful. $H$. pylori sensitivity testing and eradication therapy with appropriate antibacterial agents may contribute to accomplishment of high initial eradication rates and consequently reducing the incidence of developing gastric cancer.
\end{abstract}




\section{Keywords}

Resistance, Eradication Rate, Susceptibility Test, Clarithromycin, Metronidazole

\section{Introduction}

Helicobacter pylori ( $H$. pylori) is a microaerophilic Gram-negative spiral bacterial pathogen that resides in the human stomach in close association with the gastric epithelium. H. pylori is one of the most prevalent global pathogens and colonizes an estimated $50 \%$ of the world's population [1]. H. pylori infection is generally acquired in childhood and typically persists for life. $H$. pylori infection induces chronic gastric mucosal inflammation that contributes to the development of gastric cancer. Additionally, many strains of $H$. pylori produce the CagA oncoprotein [2]. In 1994, H. pylori was declared a class I definite human carcinogen by the WHO [3] and this classification was confirmed in 2012 [4]. Eradication therapy against $H$. pylori infection can lead to significant improvement of gastric atrophy and may prevent the development of gastric cancer [5]-[10]. However, successful rates of eradication therapy are declining and antibiotic resistance is thought to be a main cause of eradication failure [11] [12] [13]. In this study, we investigated the $H$. pylori resistance rate against clarithromycin (CAM), amoxicillin (AMPC) and metronidazole (MNZ) in pediatric patients in Japan, and evaluated eradication rates with tailored antibiotics regimens that were designed based on the results of antibiotic susceptibility tests.

\section{Methods}

\subsection{Patients and Samples}

Patients in this study were evaluated and treated at Juntendo University Hospital between 1998 and 2016. Seventy-seven patients suffering from abdominal symptoms such as epigastralgia, nausea and vomiting and from whom $H$. pylori could be isolated were included in this study. The Gastric biopsy samples for bacterial culture were taken endoscopically from both the antrum and the corpus of the stomach when evidence of gastritis or gastroduodenal ulcer was detected by esophagogastroduodenoscopy (EGDs). All patients had no history of H. pylori eradication therapy. A signed informed consent was obtained from the parents of all children before assessment with EDGs.

\subsection{Susceptibility Testing}

Antibiotic sensitivity of $H$. pylori isolates to CAM, AMPC and MNZ were examined using the dilution method with Mueller-Hinton agar plates containing $5 \%$ horse blood. The minimal inhibitory concentration (MIC) breakpoints were defined as follows; $\geq 1 \mu \mathrm{g} / \mathrm{mL}$ for CAM [14], >0.125 $\mu \mathrm{g} / \mathrm{mL}$ for AMPC [15] and $>8 \mu \mathrm{g} / \mathrm{mL}$ for $\mathrm{MNZ}[15]$. 


\subsection{Eradication Therapy}

Patients infected with CAM-sensitive strains were administered the CAM-based regimen for 7 - 14 days, which consisted of a proton pump inhibitor (PPI), AMPC (50 mg/kg per day) and CAM (20 mg/kg per day). Patients infected with CAM-resistant strains were administered the MNZ-based regimen for 7 - 14 days, which consisted of PPI, AMPC (50 mg/kg per day) and MNZ (20 mg/kg per day). We used levofloxacin for the patients with MNZ-resistant strains and minocycline for the patients with AMPC-resistant strains. H. pylori eradication was confirmed by ${ }^{13} \mathrm{C}$-urea breath test or a monoclonal stool antigen test using an enzyme-linked immuno-sorbent assay performed at least 8 weeks after treatment.

\subsection{Statistical Analysis}

Statistical analyses were performed using the chi-square test to evaluate the difference between proportions. A p-value of less than 0.05 was accepted as statistically significant.

\subsection{Conflicts of Interest}

No specific industry was linked to our study. The authors declare no conflicts of interest.

\section{Results}

\subsection{Patient Characteristics}

$H$. pylori was isolated from 77 patients with a mean age of $12.16 \pm 3.34$ years (range, 4.92 - 19.75) consisted of 40 males and 37 females. The characteristics of these 77 patients are presented in Table 1 . Antibiotic sensitivity testing was performed for CAM, AMPC and MNZ. A subset of 65 patients then underwent eradication therapy using an antibiotics regimen custom tailored for each patient based on the results of the antibiotic sensitivity tests performed on the $H$. pylori isolated from their own stomach.

\subsection{Resistance Rate to Antibiotic Agents}

The average resistance rates to CAM, AMPC and MNZ were 54.5\% (42 of 77), $6.5 \%$ (5 of 77) and 5.2\% (4 of 77) respectively (Table 2). However, when patient isolates are grouped into blocks of 4 to 5 years, the increased incidence of CAM-resistant strains becomes more obvious (Table 3). The prevalence of CAM

Table 1. Characteristics of 77 pediatric patients.

\begin{tabular}{ccc}
\hline & Number of patients & Mean age and range (year) \\
\hline Total & 77 & $12.16 \pm 3.34(4.92-19.75)$ \\
Gender & & \\
Male & 40 & $12.49 \pm 3.29(4.92-19.75)$ \\
Female & 37 & $11.80 \pm 3.39(5.00-17.17)$ \\
\hline
\end{tabular}


Table 2. Antibiotic resistance rate.

\begin{tabular}{ccc}
\hline & Number of patients & Mean age and range (year) \\
\hline Total & 77 & $12.16 \pm 3.34(4.92-19.75)$ \\
CAM & $42(54.5 \%)$ & $11.55 \pm 3.27(4.92-16.33)$ \\
AMPC & $5(6.5 \%)$ & $12.35 \pm 3.01(7.67-15.50)$ \\
MNZ & $4(5.2 \%)$ & $13.92 \pm 2.59(11.33-17.17)$ \\
\hline
\end{tabular}

Clarithromycin, CAM; amoxicillin, AMPC; metronidazole, MNZ.

Table 3. Alteration of antibiotic resistance rate.

\begin{tabular}{ccccc}
\hline & $\begin{array}{c}\text { Number of } \\
\text { patients }\end{array}$ & $\begin{array}{c}\text { Number of CAM } \\
\text { resistance }\end{array}$ & $\begin{array}{c}\text { Number of AMPC } \\
\text { resistance }\end{array}$ & $\begin{array}{c}\text { Number of MNZ } \\
\text { resistance }\end{array}$ \\
\hline $1998-2002$ & 14 & $3(21.4 \%)$ & $0(0 \%)$ & $2(14.3 \%)$ \\
$2003-2007$ & 27 & $15(55.6 \%)$ & $0(0 \%)$ & $1(3.7 \%)$ \\
$2008-2012$ & 18 & $8(44.4 \%)$ & $1(5.6 \%)$ & $1(5.6 \%)$ \\
$2013-2016$ & 18 & $16(88.9 \%)$ & $4(22.2 \%)$ & $0(0 \%)$ \\
\hline
\end{tabular}

Clarithromycin, CAM; amoxicillin, AMPC; metronidazole, MNZ.

resistant strains increased significantly over time as illustrated Figure 1. The percentage of CAM resistant strains more than doubled between the 1998-2002 and 2003-2007 time blocks $(P<0.05)$. The prevalence in the most recent block, 2013 to 2016 was $88.9 \%$, significantly higher than the other periods. The prevalence of AMPC and MNZ resistance are showed in Figure 2 and Figure 3, respectively. A small increase in AMPC resistance is observed, maximizing 22.2\% in the most recent time frame (2013-2016), but this increase was not found to be significant. MNZ resistance displayed no significant changes over time.

\subsection{Eradication Rate}

We performed tailored eradication therapy for 65 patients based upon the results of our antibiotic sensitivity testing (Table 4). Twelve patients that received eradication therapy in other hospitals or in whom the results of eradication therapy were unknown were excluded. The overall initial eradication success rate using tailored therapy was $93.8 \%$ (61 of 65 ). The eradication rate among patients infected with CAM-sensitive strains and using the CAM-based regimen was $92.6 \%$ (25 of 27). The eradication rate among patients infected with CAM-resistant strains and employing the MNZ-based regimen was $97.0 \%$ (32 of $33)$. Side effects were observed in 10 patients (15.4\%). The most common side effect was diarrhea in 5 cases $(7.7 \%)$. No severe side effect required discontinuation of eradication therapy or hospitalization.

\section{Discussion}

Although $H$. pylori infection is the main risk factor for developing gastric cancer and gastric or duodenalulcer, success in eradication therapy may lead to pre- 


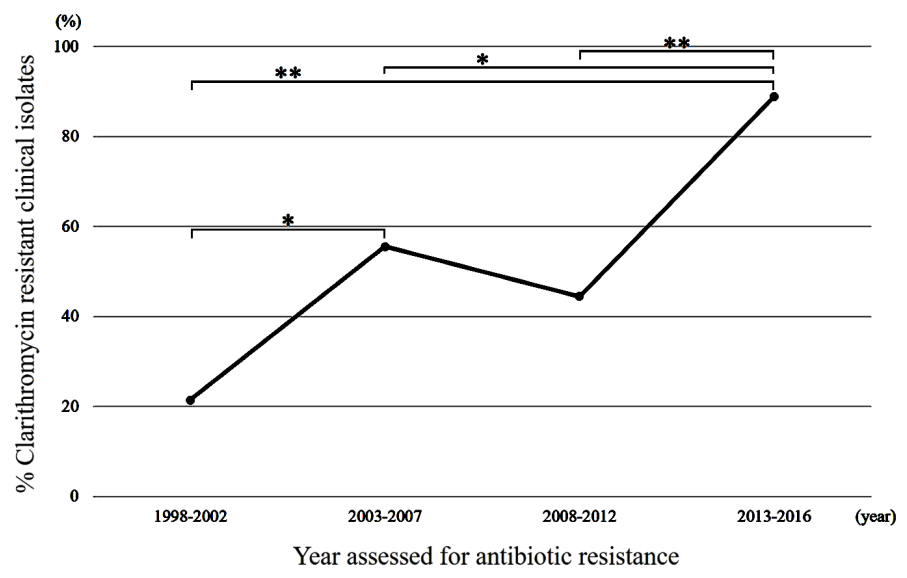

Figure 1. Incidence of clarithromycin resistant $H$. pylori in pediatric patients over time (Percentage of clarithromycin resistant clinical isolates of $H$. pylori from pediatric patients assessed from 1998-2016 as determined by in vitro minimal inhibitory concentration (MIC) breakpoints on Mueller-Hinton blood agar plates. Significant differences between year groups were determined by chi-square analysis $\left({ }^{\star} P<0.05,{ }^{\star *} P<0.01\right)$.

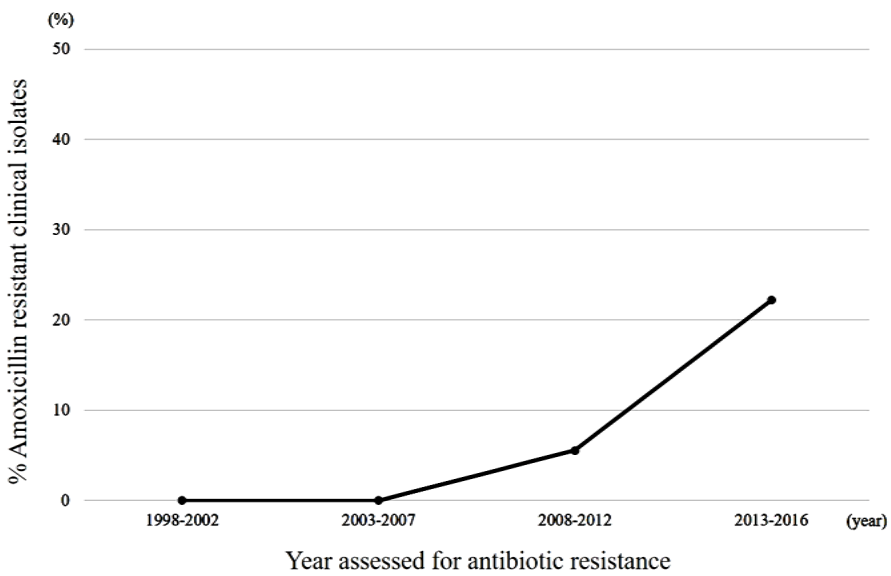

Figure 2. Incidence of amoxicillin resistant $H$. pylori in pediatric patients over time (Percentage of amoxicillin resistant clinical isolates of $H$. pylori from pediatric patients assessed from 1998-2016 as determined by in vitro minimal inhibitory concentration (MIC) breakpoints on Mueller-Hinton blood agar plates. Significant differences between year groups were determined by chi-square analysis.).

vention of these diseases [16] [17] [18]. In addition, eradication therapy for $H$. pylori infection is important for prevention of the spread of infection and may contribute to the reduction in medical expenditure on gastric diseases in the future. H. pylori eradication therapy results in improvement in gastric mucosal inflammation and atrophy, and prevention of progression of intestinal metaplasia [19]-[28], and reduces the incidence of gastric cancer [5]-[10]. On the other hand, eradication therapy does not prevent the development of metachronous gastric cancer completely [29]. Moreover, the risk of gastric cancer rises with the progress of atrophy [30] [31] [32], and Kato et al. [33] showed that gastric atrophy could develop in Japanese children of an average age of 12 years with $H$. pylori infection. In addition, we have shown significant over expression of several 


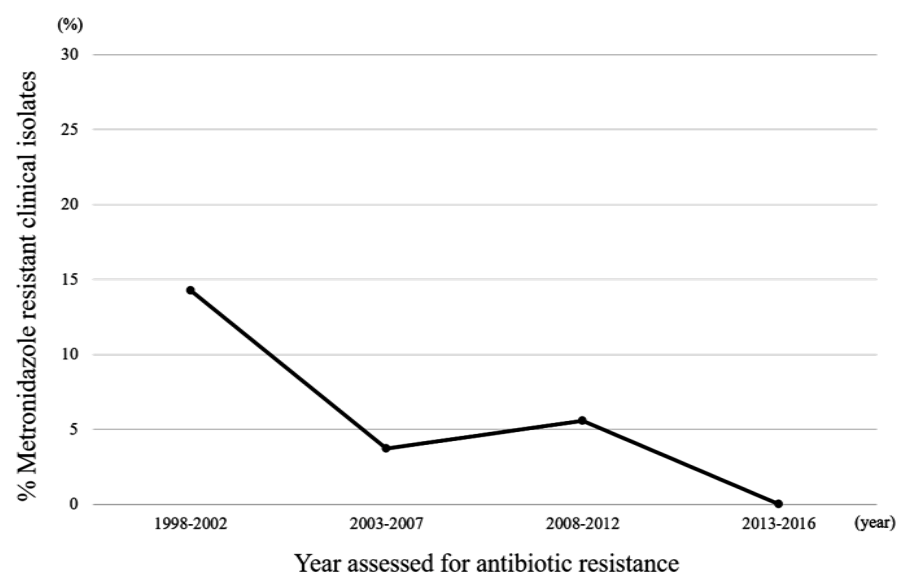

Figure 3. Incidence of metronidazole resistant $H$. pylori in pediatric patients over time (Percentage of metronidazole resistant clinical isolates of $H$. pylori from pediatric patients assessed from 1998-2016 as determined by in vitro minimal inhibitory concentration (MIC) breakpoints on Mueller-Hinton blood agar plates. Significant differences between year groups were determined by chi-square analysis.).

Table 4. Eradication rates of each resistant $H$. pylori strains.

\begin{tabular}{ccc}
\hline & Number of patients & Eradication rate \\
\hline Total & 65 & $93.8 \%$ \\
Mean age (y): $11.82 \pm 3.18$ & & \\
Range (y): $4.92-19.25$ & 27 & $92.6 \%$ \\
CAM: S, AMPC: S, MNZ: S & & \\
(PPI + AMPC + CAM therapy) & 31 & $97.0 \%$ \\
CAM: R, AMPC: S, MNZ: S & & $100 \%$ \\
(PPI + AMPC + MNZ therapy) & 1 & $75.0 \%$ \\
CAM: R, AMPC: S, MNZ: R & & \\
(PPI + AMPC + LVFX therapy) & 3 & \\
CAM: R, AMPC: R, MNZ: S & & \\
(PPI + MINO + MNZ therapy) & &
\end{tabular}

Year, y; Sensitive, S; Resistant, R; Clarithromycin, CAM; Amoxicillin, AMPC; Metronidazole, MNZ; Levofloxacin, LVFX; Minocycline, MINO.

carcinogenic molecules in the $H$. pylori infected gastric mucosa in childhood [34]. Since eradication therapy prior to the severe expansion of atrophy was shown to be significantly beneficial to prevent gastric cancer [18] [31] [33] [35], early eradication therapy especially from childhood may contribute to reduction of the incidence of gastric cancer. However, we also need careful follow-up endoscopy over the long term following $H$. pylori eradication to exclude the development of metachronous gastric cancer.

Antibiotic resistance is an important factor in treatment success. Hashinaga et al. showed the tendency for an increase in resistance rates of $H$. pylori to CAM in adult patients in Japan (18.9\% in 2002, 21.1\% in 2003, 31\% from 2010 to 2011 
and $38.5 \%$ from 2013 to 2014) [36]. Similar high resistance rates to CAM have also been documented in children in Japan, and increasing rate of primary CAM resistance has been reported. The prevalence of CAM resistance in young patients ranges from $29 \%$ - 43.4\% in Japan [37] [38] [39] [40] [41]. Kato et al. showed increasing rates of CAM resistance from $29 \%$ to $36.1 \%$ with the extension of the period for 5 years [37] [38]. Okamura et al. reported significantly higher CAM resistance rates in 2012-2013 in the young group of less than 31 years old $(57.9 \%)$ comparing to the elder group of more than 50 years old (35.1\%) [40]. In this report, a high prevalence of CAM resistance (54.5\%) was also observed, similar to past studies. However, this rate had increased significantly, and reached about $90 \%$ in most current period.

On the other hand, the prevalence of $\mathrm{MNZ}$ resistance rates in Japan is still low, about 3\% in 2013-2014 [36]. The present study also showed a low MNZ resistance rate $(5.2 \%)$ and it seemed to decrease over time. The lower rate of MNZ resistance as comparing with other countries may result from the limited use of MNZ in Japan. However, it has been pointed out that the increasing use of MNZ may lead to an increase in the incidence of MNZ resistant strains. MNZ resistance is isolated to specific geographic region with high MNZ usage [42]. Several reports suggested that excessive use of MNZ may have contributed to the increase in the emergence of MNZ resistance [43] [44]. Indeed, the acquisition of MNZ resistance after eradication therapy was suggested in a nationwide survey in Japan. The survey reported higher prevalence of MNZ resistant strains, $13.3 \%$ resistance after primary eradication therapy with PPI, AMPC and CAM and 52.4\% resistance after secondary eradication therapy with PPI, AMPC and MNZ [36]. Okamura et al. had reported the existence of a region with a higher $H$. pylori resistance rate to $\mathrm{MNZ}$ in Japan. The population of infected patients had a MNZ resistance rate of $40.2 \%$ [40]. Although it is difficult to explain why this region has such a high incidence of $M N Z$ resistant strains, it raises the possibility that increased MNZ resistance may be detected in the future, and cautious observation of susceptibility of $H$. pylori should be performed.

H. pylori eradication rates achieved with a first-line regimen of PPI, AMPC and CAM have recently fallen to about $75 \%$ because of the increasing incidence of CAM resistance in Japan [11] [13]. In addition, the $H$. pylori eradication rate decreases in patients infected with CAM resistant strains to about $40 \%$. Indeed, eradication rates in children treated with a first-line regimen of PPI, AMPC and $\mathrm{CAM}$ are also decreasing related to increased antibiotic resistance especially to CAM. In the past, multicenter studies in Japan reported $H$. pylori eradication rates in children achieving with PPI, AMPC and CAM were $70.6 \%$ to $77.4 \%$ [39] [41]. Consistent with previous studies in adults, the eradication rate has decreased in pediatric patients infected with CAM resistant strains to $40.0 \%$ $57.1 \%$ [37] [39]. Since the goal of treatment is at least a $90 \%$ eradication rate on a per-protocol basis at the first attempt [45], recent eradication rate of the firstline therapy with PPI, AMPC and CAM strongly suggests the need for new approaches. 
On the other hand, $H$. pylori eradication with a first-line regimen of PPI, AMPC and CAM in the patients infected with CAM sensitive strains showed sufficient success rates [11] [46]. In reports on pediatric patients, high eradication rates with PPI, AMPC and CAM to CAM sensitive strains were seen (91.7\% 97.1\%) [37] [39] [40]. The guidelines from the European Society for Paediatric Gastroenterology, Hepatology and Nutrition (ESPGHAN) and the North American Society for Pediatric Gastroenterology, Hepatology and Nutrition (NASPGHAN), recommend antibiotic sensitivity testing for clarithromycin before initial clarithromycin based triple therapy in areas/populations with a known high resistance rate $(>20 \%)$ of $H$. pylori to clarithromycin [47]. The present study confirms the efficacy of sensitivity testing and CAM-based regimen to CAM sensitive strains. Similar to published studies, we observed a high eradication success rate (92.6\%) with CAM-based initial treatment when applied to CAM sensitive strains. In previous studies, high eradication rates $(91.9 \%$ 96.7\%) were also obtained with tailored eradication therapy based on CAM sensitivity [40] [46] [48]. Since CAM has been used to treat children with respiratory tract infections and chronic sinusitis in Japan, CAM usage may remain at the same level and induce the development of CAM resistance in $H$. pylori in the future. Therefore, tailored eradication therapy with prior testing for antibiotic susceptibility of $H$. pylori is recommended to improve the eradication success rate.

In conclusion, CAM resistance rates of $H$. pylori in Japanese children are increasing and the high resistance rate may cause a decrease of eradication success rates with first-line therapy with PPI, AMPC and CAM. The present study is limited in geography and in patient numbers. However, these data are consistent with many reports documenting the rise in antibiotic resistant $H$. pylori. Additionally, this study provides compelling evidence for the benefits of antibiotic susceptibility screening prior to eradication therapy in order to significantly increase the efficacy of treatment. Selection of appropriate antibacterial agents with $H$. pylori susceptibility testing may contribute to achieving high primary eradication rates and the prevention of developing gastric cancer.

\section{References}

[1] Parkin, D.M. (2004) International Variation. Oncogene, 23, 6329-6340. https://doi.org/10.1038/sj.onc.1207726

[2] Hatakeyama, M. and Higashi, H. (2005) Helicobacter Pylori CagA: A New Paradigm for Bacterial Carcinogenesis. Cancer Science, 96, 835-843. https://doi.org/10.1111/j.1349-7006.2005.00130.x

[3] Bouvard, V., Baan, R., Straif, K., Grosse, Y., Secretan, B., El Ghissassi, F., Benbrahim-Tallaa, L., Guha, N., Freeman, C., Galichet, L. and Cogliano, V. (2009) A Review of Human Carcinogens-Part B: Biological Agents. The Lancet Oncology, 10, 321-322. https://doi.org/10.1016/s1470-2045(09)70096-8

[4] IARC (2012) A Review of Human Carcinogens. IARC Monographs on the Evaluation of Carcinogenic Risks to Humans, 100, 1-441.

[5] Ito, M., Takata, S., Tatsugami, M., Wada, Y., Imagawa, S., Matsumoto, Y., Takamu- 
ra, A., Kitamura, S., Matsuo, T., Tanaka, S., Haruma, K. and Chayama, K. (2009) Clinical Prevention of Gastric Cancer by Helicobacter Pylori Eradication Therapy: A Systematic Review. Journal of Gastroenterology, 44, 365-371. https://doi.org/10.1007/s00535-009-0036-8

[6] Kato, M., Asaka, M., Ono, S., Nakagawa, M., Nakagawa, S., Shimizu, Y., Chuma, M., Kawakami, H., Komatsu, Y., Hige, S. and Takeda, H. (2007) Eradication of Helicobacter Pylori for Primary Gastric Cancer and Secondary Gastric Cancer after Endoscopic Mucosal Resection. Journal of Gastroenterology, 42, 16-20.

https://doi.org/10.1007/s00535-006-1928-5

[7] Lee, Y.C., Chiang, T.H., Chou, C.K., Tu, Y.K., Liao, W.C., Wu, M.S. and Graham, D.Y. (2016) Association between Helicobacter Pylori Eradication and Gastric Cancer Incidence: A Systematic Review and Meta-Analysis. Gastroenterology, 150, 1113-1124. https://doi.org/10.1053/j.gastro.2016.01.028

[8] Ma, J.L., Zhang, L., Brown, L.M., Li, J.Y., Shen, L., Pan, K.F., Liu, W.D., Hu, Y., Han, Z.X., Crystal-Mansour, S., Pee, D., Blot, W.J., Fraumeni, J.F., Jr., You, W.C. and Gail, M.H. (2012) Fifteen-Year Effects of Helicobacter Pylori, Garlic, and Vitamin Treatments on Gastric Cancer Incidence and Mortality. Journal of the National Cancer Institute, 104, 488-492. https://doi.org/10.1093/jnci/djs003

[9] Mabe, K., Takahashi, M., Oizumi, H., Tsukuma, H., Shibata, A., Fukase, K., Matsuda, T., Takeda, H. and Kawata, S. (2009) Does Helicobacter Pylori Eradication Therapy for Peptic Ulcer Prevent Gastric Cancer. World Journal of Gastroenterology, 15, 4290-4297. https://doi.org/10.3748/wjg.15.4290

[10] Take, S., Mizuno, M., Ishiki, K., Hamada, F., Yoshida, T., Yokota, K., Okada, H. and Yamamoto, K. (2015) Seventeen-Year Effects of Eradicating Helicobacter Pylori on the Prevention of Gastric Cancer in Patients with Peptic Ulcer; a Prospective Cohort Study. Journal of Gastroenterology, 50, 638-644. https://doi.org/10.1007/s00535-014-1004-5

[11] Kobayashi, I., Murakami, K., Kato, M., Kato, S., Azuma, T., Takahashi, S., Uemura, N., Katsuyama, T., Fukuda, Y., Haruma, K., Nasu, M. and Fujioka, T. (2007) Changing Antimicrobial Susceptibility Epidemiology of Helicobacter pylori Strains in Japan between 2002 and 2005. Journal of Clinical Microbiology, 45, 4006-4010. https://doi.org/10.1128/JCM.00740-07

[12] Murakami, K., Sakurai, Y., Shiino, M., Funao, N., Nishimura, A. and Asaka, M. (2016) Vonoprazan, a Novel Potassium-Competitive Acid Blocker, as a Component of First-Line and Second-Line Triple Therapy for Helicobacter pylori Eradication: A Phase III, Randomised, Double-Blind Study. Gut, 65, 1439-1446. https://doi.org/10.1136/gutjnl-2015-311304

[13] Nishizawa, T., Maekawa, T., Watanabe, N., Harada, N., Hosoda, Y., Yoshinaga, M., Yoshio, T., Ohta, H., Inoue, S., Toyokawa, T., Yamashita, H., Saito, H., Kuwai, T., Katayama, S., Masuda, E., Miyabayashi, H., Kimura, T., Nishizawa, Y., Takahashi, M. and Suzuki, H. (2015) Clarithromycin versus Metronidazole as First-Line Helicobacter pylori Eradication: A Multicenter, Prospective, Randomized Controlled Study in Japan. Journal of Clinical Gastroenterology, 49, 468-471.

[14] Chemotherapy, J.S.F. (2000) Antimicrobial Susceptibility Subcommittee on Helicobacter pylori MIC Breakpoints for Clarithromycin and Amoxicillin. Japan Society of Chemotherapy, 48, 561-567.

[15] Testing, E.C.A.S. (2017) Breakpoint Tables for Interpretation of MICs and Zone Diameters, Version 7.0 ed.

[16] Fukase, K., Kato, M., Kikuchi, S., Inoue, K., Uemura, N., Okamoto, S., Terao, S., Amagai, K., Hayashi, S. and Asaka, M. (2008) Effect of Eradication of Helicobacter 
pylori on Incidence of Metachronous Gastric Carcinoma after Endoscopic Resection of Early Gastric Cancer: An Open-Label, Randomised Controlled Trial. The Lancet, 372, 392-397.

[17] Gisbert, J.P., Khorrami, S., Carballo, F., Calvet, X., Gene, E. and Dominguez-Munoz, E. (2004) Meta-Analysis: Helicobacter pylori Eradication Therapy vs. Antisecretory Non-Eradication Therapy for the Prevention of Recurrent Bleeding from Peptic Ulcer. Alimentary Pharmacology \& Therapeutics, 19, 617-629. https://doi.org/10.1111/j.1365-2036.2004.01898.x

[18] Wong, B.C., Lam, S.K., Wong, W.M., Chen, J.S., Zheng, T.T., Feng, R.E., Lai, K.C., Hu, W.H., Yuen, S.T., Leung, S.Y., Fong, D.Y., Ho, J., Ching, C.K. and Chen, J.S. (2004) Helicobacter pylori Eradication to Prevent Gastric Cancer in a High-Risk Region of China: A Randomized Controlled Trial. JAMA, 291, 187-194.

https://doi.org/10.1001/jama.291.2.187

[19] Correa, P., Fontham, E.T., Bravo, J.C., Bravo, L.E., Ruiz, B., Zarama, G., Realpe, J. L., Malcom, G.T., Li, D., Johnson, W.D. and Mera, R. (2000) Chemoprevention of Gastric Dysplasia: Randomized Trial of Antioxidant Supplements and Anti-Helicobacter pylori Therapy. Journal of the National Cancer Institute, 92, 18811888. https://doi.org/10.1093/jnci/92.23.1881

[20] Iijima, K., Ohara, S., Sekine, H., Koike, T., Kato, K., Asaki, S., Shimosegawa, T. and Toyota, T. (2000) Changes in Gastric Acid Secretion Assayed by Endoscopic Gastrin Test before and after Helicobacter pylori Eradication. The Gut, 46, 20-26. https://doi.org/10.1136/gut.46.1.20

[21] Kang, J.M., Kim, N., Shin, C.M., Lee, H.S., Lee, D.H., Jung, H.C. and Song, I.S. (2012) Predictive Factors for Improvement of Atrophic Gastritis and Intestinal Metaplasia after Helicobacter pylori Eradication: A Three-Year Follow-Up Study in Korea. Helicobacter, 17, 86-95. https://doi.org/10.1111/j.1523-5378.2011.00918.x

[22] Kato, M., Terao, S., Adachi, K., Nakajima, S. ando, T., Yoshida, N., Uedo, N., Murakami, K., Ohara, S., Ito, M., Uemura, N., Shimbo, T., Watanabe, H., Kato, T. and Ida, K. (2013) Changes in Endoscopic Findings of Gastritis after Cure of H. pylori Infection: Multicenter Prospective Trial. Digestive Endoscopy: Official Journal of the Japan Gastroenterological Endoscopy Society, 25, 264-273.

[23] Kodama, M., Murakami, K., Okimoto, T., Sato, R., Uchida, M., Abe, T., Shiota, S., Nakagawa, Y., Mizukami, K. and Fujioka, T. (2012) Ten-Year Prospective Follow-Up of Histological Changes at Five Points on the Gastric Mucosa as Recommended by the Updated Sydney System after Helicobacter pylori Eradication. Jour nal of Gastroenterology, 47, 394-403. https://doi.org/10.1007/s00535-011-0504-9

[24] Ohkusa, T., Fujiki, K., Takashimizu, I., Kumagai, J., Tanizawa, T., Eishi, Y., Yokoyama, T. and Watanabe, M. (2001) Improvement in Atrophic Gastritis and Intestinal Metaplasia in Patients in Whom Helicobacter pylori Was Eradicated. Annals of Internal Medicine, 134, 380-386. https://doi.org/10.7326/0003-4819-134-5-200103060-00010

[25] Rokkas, T., Pistiolas, D., Sechopoulos, P., Robotis, I. and Margantinis, G. (2007) The Long-Term Impact of Helicobacter pylori Eradication on Gastric Histology: A Systematic Review and Meta-Analysis. Helicobacter, 12, 32-38. https://doi.org/10.1111/j.1523-5378.2007.00563.x

[26] Sung, J.J., Lin, S.R., Ching, J.Y., Zhou, L.Y., To, K.F., Wang, R.T., Leung, W.K., Ng, E.K., Lau, J.Y., Lee, Y.T., Yeung, C.K., Chao, W. and Chung, S.C. (2000) Atrophy and Intestinal Metaplasia One Year after Cure of H. pylori Infection: A Prospective, Randomized Study. Gastroenterology, 119, 7-14. https://doi.org/10.1053/gast.2000.8550

[27] Wang, J., Xu, L., Shi, R., Huang, X., Li, S.W., Huang, Z. and Zhang, G. (2011) Gas- 
tric Atrophy and Intestinal Metaplasia before and after Helicobacter pylori Eradication: A Meta-Analysis. Digestion, 83, 253-260. https://doi.org/10.1159/000280318

[28] Watanabe, H., Yamaguchi, N., Kuwayama, H., Sekine, C., Uemura, N., Kaise, M., Nakamura, T., Kubo, M., Yoshida, S., Haruma, K., Inoue, M., Shimatani, T., Sanuki, E., Mieno, H., Kawanishi, M., Nakazawa, S. and Tanaka, T. (2003) Improvement in Gastric Histology Following Helicobacter pylori Eradication Therapy in Japanese Peptic Ulcer Patients. The Journal of International Medical Research, 31, 362-369. https://doi.org/10.1177/147323000303100502

[29] Maehata, Y., Nakamura, S., Fujisawa, K., Esaki, M., Moriyama, T., Asano, K., Fuyuno, Y., Yamaguchi, K., Egashira, I., Kim, H., Kanda, M., Hirahashi, M. and Matsumoto, T. (2012) Long-Term Effect of Helicobacter pylori Eradication on the Development of Metachronous Gastric Cancer after Endoscopic Resection of Early Gastric Cancer. Gastrointestinal Endoscopy, 75, 39-46.

[30] Masuyama, H., Yoshitake, N., Sasai, T., Nakamura, T., Masuyama, A., Zuiki, T., Kurashina, K., Mieda, M., Sunada, K., Yamamoto, H., Togashi, K., Terano, A. and Hiraishi, H. (2015) Relationship between the Degree of Endoscopic Atrophy of the Gastric Mucosa and Carcinogenic Risk. Digestion, 91, 30-36. https://doi.org/10.1159/000368807

[31] Take, S., Mizuno, M., Ishiki, K., Nagahara, Y., Yoshida, T., Yokota, K. and Oguma, K. (2007) Baseline Gastric Mucosal Atrophy Is a Risk Factor Associated with the Development of Gastric Cancer after Helicobacter pylori Eradication Therapy in Patients with Peptic Ulcer Diseases. Journal of Gastroenterology, 42, 21-27. https://doi.org/10.1007/s00535-006-1924-9

[32] Uemura, N., Okamoto, S., Yamamoto, S., Matsumura, N., Yamaguchi, S., Yamakido, M., Taniyama, K., Sasaki, N. and Schlemper, R.J. (2001) Helicobacter pylori Infection and the Development of Gastric Cancer. The New England Journal of Medicine, 345, 784-789. https://doi.org/10.1056/NEJMoa001999

[33] Kato, S., Kikuchi, S. and Nakajima, S. (2008) When Does Gastric Atrophy Develop in Japanese chIldren? Helicobacter, 13, 278-281.

https://doi.org/10.1111/j.1523-5378.2008.00611.x

[34] Obayashi, N., Ohtsuka, Y., Hosoi, K., Ikuse, T., Jimbo, K., Aoyagi, Y., Fujii, T., Kudo, T., Asaoka, D., Hojo, M., Nagahara, A., Watanabe, S. and Shimizu, T. (2016) Comparison of Gene Expression between Pediatric and Adult Gastric Mucosa with Helicobacter pylori Infection. Helicobacter, 21, 114-123. https://doi.org/10.1111/hel.12245

[35] Sugano, K., Tack, J., Kuipers, E.J., Graham, D.Y., El-Omar, E.M., Miura, S., Haruma, K., Asaka, M., Uemura, N. and Malfertheiner, P. (2015) Kyoto Global Consensus Report on Helicobacter pylori Gastritis. Gut, 64, 1353-1367. https://doi.org/10.1136/gutjnl-2015-309252

[36] Hashinaga, M., Okimoto, T., Kodama, M., Mizukami, K., Ogawa, R., Okamoto, K., Shutou, M., Fukuda, K., Sonoda, A., Fukuda, M., Honda, S., Yamaoka, Y. and Murakami, K. (2016) Drug Resistance in Japan; The Presesnt Status of Helicobacter pylori; The Totaled Results of the Resistant Strain Survey in 2013 and 2014, Wagakunini okeru yakuzaitaisei Helicobacter pylori no Genjo-2013-2014 nendo taiseikin surveillance no syuukei houkoku. Japanese Journal of Helicobacter Research, 17, 45-49.

[37] Kato, S. and Fujimura, S. (2010) Primary Antimicrobial Resistance of Helicobacter pylori in Children during the Past 9 Years. Pediatrics International, 52, 187-190. https://doi.org/10.1111/j.1442-200X.2009.02915.x

[38] Kato, S., Fujimura, S., Udagawa, H., Shimizu, T., Maisawa, S., Ozawa, K. and Iinu- 
ma, K. (2002) Antibiotic Resistance of Helicobacter pylori Strains in Japanese Children. Journal of Clinical Microbiology, 40, 649-653. https://doi.org/10.1128/JCM.40.2.649-653.2002

[39] Kato, S., Konno, M., Maisawa, S., Tajiri, H., Yoshimura, N., Shimizu, T., Toyoda, S., Nakayama, Y. and Iinuma, K. (2004) Results of Triple Eradication Therapy in Japanese Children: A Retrospective Multicenter Study. Journal of Gastroenterology, 39, 838-843. https://doi.org/10.1007/s00535-004-1398-6

[40] Okamura, T., Suga, T., Nagaya, T., Arakura, N., Matsumoto, T., Nakayama, Y. and Tanaka, E. (2014) Antimicrobial Resistance and Characteristics of Eradication Therapy of Helicobacter pylori in Japan: A Multi-Generational Comparison. Helicobacter, 19, 214-220. https://doi.org/10.1111/hel.12124

[41] Okuda, M., Kikuchi, S., Mabe, K., Osaki, T., Kamiya, S., Fukuda, Y. and Kato, M. (2017) Nationwide Survey of Helicobacter pylori Treatment for Children and Adolescents in Japan. Pediatrics International, 59, 57-61.

https://doi.org/10.1111/ped.13038

[42] Glupczynski, Y. (1998) Antimicrobial Resistance in Helicobacter pylori: A Global Overview. Acta Gastro-Enterologica Belgica, 61, 357-366.

https://doi.org/10.1007/978-94-011-4882-5_42

[43] Kim, J.J., Reddy, R., Lee, M., Kim, J.G., El-Zaatari, F.A., Osato, M.S., Graham, D.Y. and Kwon, D.H. (2001) Analysis of Metronidazole, Clarithromycin and Tetracycline Resistance of Helicobacter pylori Isolates from Korea. Journal of Antimicrobial Chemotherapy, 47, 459-461. https://doi.org/10.1093/jac/47.4.459

[44] Ueki, N., Miyake, K., Kusunoki, M., Shindo, T., Kawagoe, T., Futagami, S., Tsukui, T., Inagaki, H. and Sakamoto, C. (2009) Impact of Quadruple Regimen of Clarithromycin Added to Metronidazole-Containing Triple Therapy against Helicobacter pylori Infection Following Clarithromycin-Containing Triple-Therapy Failure. $\mathrm{He}$ licobacter, 14, 91-99. https://doi.org/10.1111/j.1523-5378.2009.00664.x

[45] Graham, D.Y., Lu, H. and Yamaoka, Y. (2007) A Report Card to Grade Helicobacter pylori Therapy. Helicobacter, 12, 275-278. https://doi.org/10.1111/j.1523-5378.2007.00518.x

[46] Sugimoto, M., Uotani, T., Sahara, S., Ichikawa, H., Yamade, M., Sugimoto, K. and Furuta, T. (2014) Efficacy of Tailored Helicobacter pylori Eradication Treatment Based on Clarithromycin Susceptibility and Maintenance of Acid Secretion. Helicobacter, 19, 312-318. https://doi.org/10.1111/hel.12128

[47] Koletzko, S., Jones, N.L., Goodman, K.J., Gold, B., Rowland, M., Cadranel, S., Chong, S., Colletti, R.B., Casswall, T., Elitsur, Y., Guarner, J., Kalach, N., Madrazo, A., Megraud, F., Oderda, G. and H pylori Working Groups of ESPGHAN and NASPGHAN (2011) Evidence-Based Guidelines from ESPGHAN and NASPGHAN for Helicobacter pylori Infection in Children. Journal of Pediatric Gastroenterology and Nutrition, 53, 230-243.

[48] Kawai, T., Yamagishi, T., Yagi, K., Kataoka, M., Kawakami, K., Sofuni, A., Itoi, T., Sakai, Y., Moriyasu, F., Osaka, Y., Takagi, Y., Aoki, T., Rimbara, E., Noguchi, N. and Sasatsu, M. (2008) Tailored Eradication Therapy Based on Fecal Helicobacter pylori Clarithromycin Sensitivities. Journal of Gastroenterology and Hepatology, 23, S171-S174. https://doi.org/10.1111/j.1440-1746.2008.05408.x 
Submit or recommend next manuscript to SCIRP and we will provide best service for you:

Accepting pre-submission inquiries through Email, Facebook, LinkedIn, Twitter, etc. A wide selection of journals (inclusive of 9 subjects, more than 200 journals)

Providing 24-hour high-quality service

User-friendly online submission system

Fair and swift peer-review system

Efficient typesetting and proofreading procedure

Display of the result of downloads and visits, as well as the number of cited articles Maximum dissemination of your research work

Submit your manuscript at: http://papersubmission.scirp.org/

Or contact aim@scirp.org 